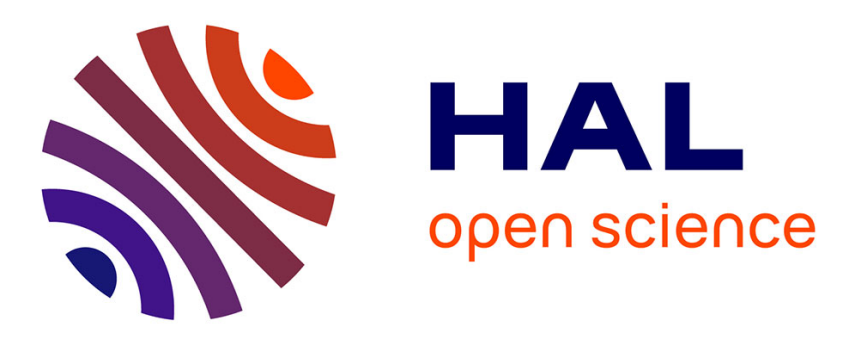

\title{
Time dependent critical field transition line in an insulating spin-glass
}

\author{
N. Bontemps, J. Rajchenbach, R. Orbach
}

\section{To cite this version:}

N. Bontemps, J. Rajchenbach, R. Orbach. Time dependent critical field transition line in an insulating spin-glass. Journal de Physique Lettres, 1983, 44 (1), pp.47-52. 10.1051/jphyslet:0198300440104700 . jpa-00232141

\section{HAL Id: jpa-00232141 https://hal.science/jpa-00232141}

Submitted on 1 Jan 1983

HAL is a multi-disciplinary open access archive for the deposit and dissemination of scientific research documents, whether they are published or not. The documents may come from teaching and research institutions in France or abroad, or from public or private research centers.
L'archive ouverte pluridisciplinaire HAL, est destinée au dépôt et à la diffusion de documents scientifiques de niveau recherche, publiés ou non, émanant des établissements d'enseignement et de recherche français ou étrangers, des laboratoires publics ou privés. 
Classification

Physics Abstracts

$75.40-64.60-78.20 \mathrm{~L}$

\title{
Time dependent critical field transition line in an insulating spin-glass
}

\author{
N. Bontemps, J. Rajchenbach and R. Orbach $\left(^{*}\right)$ \\ Laboratoire d'Optique Physique, E.S.P.C.I., 10, rue Vauquelin, 75231 Paris Cedex 05, France
}

(Reçu le 13 septembre 1982, révisé le 25 octobre, accepté le 8 novembre 1982)

\begin{abstract}
Résumé. - Nous avons analysé le retour à l'équilibre de l'aimantation dans $\mathrm{Eu}_{0,4} \mathrm{Sr}_{0,6} \mathrm{~S}$ pour différents temps de mesure (1 ms-1 s) après coupure d'un petit champ magnétique superposé à un grand champ statique. Nous déduisons, pour les diverses échelles de temps, différentes lignes de transition champ-température, qui chacune suit la loi de De Almeida-Thouless. L'échelle de champ dépend (ne dépend pas) du temps pour des temps de mesure supérieurs (inférieurs) à $10 \mathrm{~ms}$. Nous proposons une interprétation des résultats au vu de récentes théories.
\end{abstract}

\begin{abstract}
The change in magnetization of the insulating spin-glass $\mathrm{Eu}_{0.4} \mathrm{Sr}_{0.6} \mathrm{~S}$ has been measured as a function of time $(1 \mathrm{~ms}-1 \mathrm{~s})$ for small magnetic field changes superposed on a larger constant field. A set of field-temperature transition lines has been obtained for different time scales. Each appears to be of the De Almeida-Thouless form but with a field scale which is dependent (independent) of the time scale for times $>(<) 10 \mathrm{~ms}$. The results are analysed in terms of recent theories.
\end{abstract}

The time scale for a continuous distribution of spin-glass order parameters $q(x)$ has recently been related to the Parisi [1] parameter $x$ by Sompolinsky [2]. The short time spin-glass behaviour obeys linear response (the dynamic region) while the long time behaviour exhibits the thermodynamic limit (the static region). We report here measurements which may relate to these theories, in that they show explicitly a time dependence of the field-temperature $(H-T)$ line.

We have measured the spin-glass critical field as a function of temperature at different experimental time scales in the system $\mathrm{Eu}_{0.4} \mathrm{Sr}_{0.6} \mathrm{~S}$ using the Faraday rotation technique. The critical field was defined as that field, $H_{\mathrm{c}}$, which was required for the magnetization to appear reversible with reference to the paramagnetic response on the time scale $t_{\mathrm{m}}$ of our experiments. A family of curves for $H_{\mathrm{c}}$ versus $T$ for different $t_{\mathrm{m}}$ can be drawn through the experimental points according to a relation of the form :

$$
\left\{f\left(t_{\mathrm{m}}\right)\left[g \beta H_{\mathrm{c}} / k T_{\mathrm{G}}^{0}\left(t_{\mathrm{m}}\right)\right]\right\}^{\alpha}=(4 / 5)^{1 / 3}\left[1-T / T_{\mathrm{G}}^{0}\left(t_{\mathrm{m}}\right)\right]
$$

with $\alpha=0.63 \pm 0.07 . T_{\mathrm{G}}^{0}\left(t_{\mathrm{m}}\right)$ is the $H=0$ spin-glass transition temperature also determined in our experiments; $f\left(t_{\mathrm{m}}\right) \sim 13$ for $t_{\mathrm{m}}=1$ or $10 \mathrm{~ms}$ and increases for longer time $\left[f\left(t_{\mathrm{m}}=1 \mathrm{~s}\right) \sim 27\right]$.

(*) Permanent address : Department of Physics, University of California, Los Angeles AC, 90024, U.S.A. 
The form of equation (1) (except for the time dependent prefactor $f\left(t_{\mathrm{m}}\right)$ ) is that first proposed by De Almeida and Thouless [3] for Ising spins, and extended to Heisenberg spins for the longitudinal susceptibility by Gabay and Toulouse [4] (hence the prefactor $(4 / 5)^{1 / 3}$ ). This " transition " line is now thought to represent a cross-over from transverse to longitudinal spin freezing [5]. Nevertheless our results appear to exhibit a change in behaviour of the longitudinal magnetization across such a line. That $\left[1-T / T_{\mathrm{G}}^{0}\left(t_{\mathrm{m}}\right)\right]$ should scale as $\left[g \beta H_{\mathrm{c}} / k T_{\mathrm{G}}^{0}\left(t_{\mathrm{m}}\right)\right]^{2 / 3}$, regardless of the time scale of the experiment, was first suggested by Chamberlin et al. [6].

The sample was a single crystal platelet of $\mathrm{Eu}_{0.4} \mathrm{Sr}_{0.6} \mathrm{~S}\left(4 \times 3 \times 0.7 \mathrm{~mm}^{3}\right)$ oriented perpendicular to the magnetic field. At a given temperature $T$, an external field was applied ( 0 to $500 \mathrm{Oe})$ and a small field $(\Delta H \sim 2 \mathrm{Oe})$ superposed the latter switched off and on. Because of the sample geometry, the demagnetizing field is very large. Assuming the sample to be a quasi-infinite platelet, we estimate that it approximates to $85 \%$ of the applied field in the range where $M$ and $H$ remain proportional. As this is the case in the regime of fields we have used, only the absolute value of the field is affected. We take this " correction " into account in our subsequent analysis. The change in magnetization $\Delta M\left(H, T, t_{\mathrm{m}}\right)$ was measured by means of Faraday rotation at a time $t_{\mathrm{m}}$ after the change in the small field $\Delta H$. The time scale $t_{\mathrm{m}}$ was varied from $1 \mathrm{~ms}$ to $1 \mathrm{~s}$, the repetition rate for the field off-field on sequence was $\sim 20 t_{\mathrm{m}}$. The temperature range was 1.3-1.8 $\mathrm{K}$.

The principle of a sensitive device for measuring the Faraday rotation has been described in reference [7]. This device has been adapted as described in references [8] in order to perform measurements over a large range of times. The signal associated with the change $\Delta H$ was fed into a multichannel analyser where it was averaged to reach the desired sensitivity. The smallest rotation angle that we were then able to detect, with reference to our noise level, was $10^{-3}$ degree (this would correspond, for the $\mathrm{Eu}_{0.4} \mathrm{Sr}_{0.6} \mathrm{~S}$ sample, to an applied magnetic field of $2 \times 10^{-3} \mathrm{Oe}$ ). The magnitude of $\Delta H$ was kept constant so that any transient circuit non-linearities would remain the same as $H$ is changed.

We refered our magnetization (rotation) measurements as a function of time to high temperature measurements (at the same field $H$ and time scale $t_{\mathrm{m}}$ ) in order to establish a comparison with the paramagnetic response. For a fixed time scale $t_{\mathrm{m}}$ at temperature $T$, we found that for all $H \geqslant H_{\mathrm{c}}$, the change in magnetization caused by $\Delta H$

$$
\Delta M\left(H, T, t_{\mathrm{m}}\right)=0
$$

to within our experimental accuracy, thus defining $H_{\mathrm{c}}(T)$. In this way we were able to map out the $H=H_{\mathrm{c}}\left(T, t_{\mathrm{m}}\right)$ line. Figure 1 exhibits an example of our experimental curves for the Faraday rotation angle $\Delta \theta$ (proportional to $\Delta M$ ) for a given time scale $(1 \mathrm{~ms})$ and temperature $(1.576 \mathrm{~K})$ with varying applied static fields. The manner in which we extract the critical field from such data

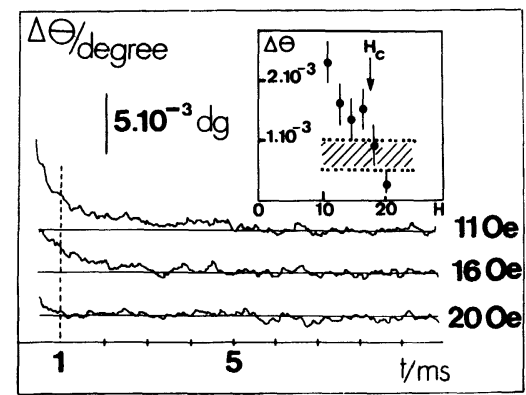

Fig. 1. - Experimental decay of the Faraday rotation angle $\Delta \theta$ as a function of time in the range $1 \mathrm{~ms}-10 \mathrm{~ms}$, for various applied fields. The insert shows the plot of $\Delta \theta\left(t_{\mathrm{m}}=1 \mathrm{~ms}\right)$ versus $H$; the hatched part indicates the criterion for the determination of $H_{\mathrm{c}} \cdot T=1.576 \mathrm{~K}$. 
is illustrated in the insert. $\Delta \theta$ is measured at $t=t_{\mathrm{m}}$, with reference to the equilibrium value, and plotted versus $H . H_{\mathrm{c}}$ is defined by $5 \times 10^{-3} \mathrm{deg} .<\Delta \theta\left(H_{\mathrm{c}}, t_{\mathrm{m}}\right)<10^{-3} \mathrm{deg}$. The uncertainty on $H_{\mathrm{c}}$ introduced by this procedure does not exceed $2 \mathrm{Oe}$. This temperature is stabilized within $\pm 10^{-3} \mathrm{~K}$.

The raw experimental points $\left(H_{\mathrm{c}} v s . T_{\mathrm{c}}\right)$ are reported on figure 2 for four different delay times $t_{\mathrm{m}}$. Our curves extrapolate to various zero field freezing temperature $T_{\mathrm{G}}^{0}\left(t_{\mathrm{m}}\right)$ for different $t_{\mathrm{m}}$. With our procedure, we cannot experimentally approach $T_{\mathrm{G}}^{0}\left(t_{\mathrm{m}}\right)$ closer than a few hundredths of a degree $\mathrm{K}$. The choice of $T_{\mathrm{G}}^{0}\left(t_{\mathrm{m}}\right)$ will be of importance later when we plot our data in reduced units, so that the method of its determination deserves some attention. Unfortunately we could not rely on previous susceptibility measurements [9] to locate $T_{\mathrm{G}}^{0}\left(t_{\mathrm{m}}\right)$ accurately. Though the strong frequency dependence of the a.c. susceptibility maximum as a function of temperature is fully consistent with our results, it is not obvious that $T_{\mathrm{G}}^{0}\left(t_{\mathrm{m}}\right)$ is to be associated with the maximum of the a.c. susceptibility for the corresponding frequency. We thus used a different procedure to determine $T_{\mathrm{G}}^{0}\left(t_{\mathrm{m}}\right)$. Actually, the $T_{\mathrm{G}}^{0}\left(t_{\mathrm{m}}\right)$ values that we shall estimate as described further are very close $\left(2 \times 10^{-2} \mathrm{~K}\right)$ to those previously determined [9].

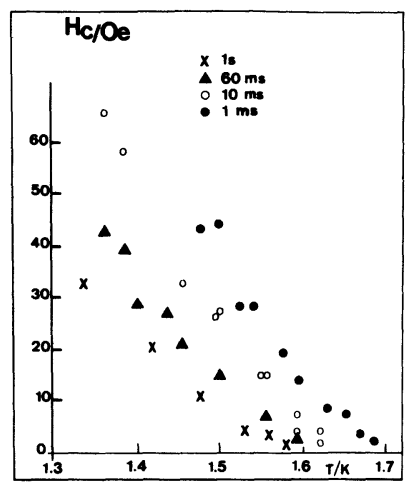

Fig. 2. - Experimental values of $H_{\mathrm{c}}$ versus temperature $T$ for $t_{\mathrm{m}}=1 \mathrm{~ms}$ (full circles), $10 \mathrm{~ms}$ (open circles), $60 \mathrm{~ms}$ (triangles), and $1 \mathrm{~s}$ (crosses).

We found that the experimental critical field points fit a power law $H_{\mathrm{c}}^{\alpha}\left(t_{\mathrm{m}}\right) \sim 1-T / T_{\mathrm{G}}^{0}\left(t_{\mathrm{m}}\right)$ where $T_{\mathrm{G}}^{0}\left(t_{\mathrm{m}}\right)$ lies within an experimental uncertainty range. Choosing Log-Log coordinates, we calculated $\alpha$ by linear regression of the experimental points, and for various $T_{\mathrm{G}}^{0}\left(t_{\mathrm{m}}\right)$. We then searched for the value of $T_{\mathrm{G}}^{0}\left(t_{\mathrm{m}}\right)$ which maximized the linear regression coefficient $r(1>r>0.98)$. Values of $r, \alpha$ and $T_{\mathrm{G}}^{0}\left(t_{\mathrm{m}}\right)$ are reported in table $\mathrm{I}$ for the various experimental time scales $t_{\mathrm{m}}$. Remarkably, $\alpha$ is found to be constant to within our experimental error and close to the De Almeida-Thouless value of 0.67 whatever $t_{\mathrm{m}}$. (This is not quite true for $t_{\mathrm{m}}=1 \mathrm{~s}$, but note that there are only 6 experimental points so that the fit may be somewhat less reliable.) Once having determined $T_{\mathrm{G}}^{0}\left(t_{\mathrm{m}}\right)$, we may plot our measured $H_{\mathrm{c}} v s$. $T_{\mathrm{c}}$ in reduced units $h=g \beta H_{\mathrm{c}} / k T_{\mathrm{G}}^{0}\left(t_{\mathrm{m}}\right)$ and $T / T_{\mathrm{G}}^{0}\left(t_{\mathrm{m}}\right):$ these are exhibited in figure 3 . We point out that the reduced units remove the time dependent effects due to the time dependence of $T_{\mathrm{G}}^{0}$, and thus may exhibit a relation between time and field. In the range $t_{\mathrm{m}}>10 \mathrm{~ms}$, the $h v s . T / T_{\mathrm{G}}^{0}\left(t_{\mathrm{m}}\right)$ curves are significantly different, showing unambiguously that the critical field $h$ depends on the time scale of the experiment in this range of time. However, for the $1 \mathrm{~ms}$ and $10 \mathrm{~ms}$ time scales, the curves appear to coalesce. This suggests that a minimum time scale exists for $\mathrm{Eu}_{0.4} \mathrm{Sr}_{0.6} \mathrm{~S}\left(t_{\mathrm{m}}<10 \mathrm{~ms}\right)$, so that $f\left(t_{\mathrm{m}}\right)$ is independent of time for $t_{\mathrm{m}}<10 \mathrm{~ms}$.

One could object to our use of a small field increment $\Delta H$, on top of a large static field $H$, to search for the spin-glass « transition ». That is, one could argue that we only sample the response around a local minimum in configuration space, with different physical properties than the tran- 
Table I. - Experimental values of the zero field freezing temperature $T_{\mathrm{G}}^{0}\left(t_{\mathrm{m}}\right)$, of the exponent $\alpha$, and of the linear regression coefficient $r$ for the various experimental time scales $t_{\mathrm{m}}$. The values of $T_{\mathrm{G}}^{0}\left(t_{\mathrm{m}}\right)$ and $\alpha$ correspond to the maximum of $r$, and the uncertainty range to the admitted range for $r$ (column 4). An estimate of the subsequent uncertainty for $h=g \beta H / k T_{\mathrm{G}}^{0}\left(t_{\mathrm{m}}\right)$ and $T / T_{\mathrm{G}}^{0}\left(t_{\mathrm{m}}\right)$ is indicated on figure 3.

\begin{tabular}{|c|c|c|c|c|}
\multicolumn{1}{c}{$t_{\mathrm{m}}$} & $T_{\mathrm{G}}^{0}\left(t_{\mathrm{m}}\right)$ & $\alpha$ & & $h_{\text {theo }} / h_{\text {exp }}$ \\
\hline $1 \mathrm{~ms}$ & $1.720 \pm \begin{array}{l}0.010 \\
0.010\end{array}$ & $0.62 \pm \begin{array}{l}0.08 \\
0.07\end{array}$ & $\geqslant 0.993$ & 13 \\
\hline $10 \mathrm{~ms}$ & $1.655 \pm \begin{array}{l}0.015 \\
0.005\end{array}$ & $0.64 \pm 0.05$ \\
0.09 & $\geqslant 0.976$ & 13 \\
\hline $60 \mathrm{~ms}$ & $1.647 \pm \begin{array}{l}0.013 \\
0.007\end{array}$ & $0.65 \pm 0.06$ & $\geqslant 0.996$ & 19 \\
\hline $1 \mathrm{~s}$ & $1.630 \pm 0.010$ & $0.57 \pm 0.05$ & $\geqslant 0.995$ & 27 \\
\hline
\end{tabular}

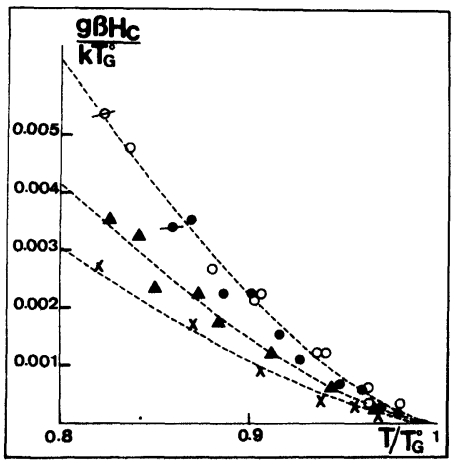

Fig. 3. - Reduced critical field $h=g \beta H_{\mathrm{c}} / k T_{\mathrm{G}}^{0}\left(t_{\mathrm{m}}\right)$ versus reduced temperature $T / T_{\mathrm{G}}^{0}\left(t_{\mathrm{m}}\right)$. The symbols are the same as in figure 2 . The bars indicate the range of variation of the reduced data corresponding to the uncertainty range of $T_{\mathrm{G}}^{0}\left(t_{\mathrm{m}}\right)$. The dashed lines are fitted to the experimental points with the $f\left(t_{\mathrm{m}}\right)$ factors listed in table $I$ and $\alpha=0.67$.

sition to the true equilibrium state. However, as already argued previously [6], such a behaviour would imply the existence of a minimum threshold field below which no irreversible phenomena occur. Such a field has never been identified. We believe therefore that we are probing the change of irreversible behaviour as a whole. Nevertheless, it would be useful to perform the same experiments but change $H$ from 0 to $H_{\mathrm{c}}$. Transient problems have so far prevented us from doing so, though we do point out that the behaviour at low field $(H \simeq 10 \mathrm{Oe} \sim 5 \Delta H)$ does appear to fall on the same curve as for large $H(H \simeq 300 \mathrm{Oe} \gg \Delta H)$ (See Figs. 2 and 3). We now turn to a comparison with such theoretical results as are available.

The Ising model analysis of Thouless, De Almeida and Kosterlitz [10], using a Parisi approach in a finite field, finds an instability in the high temperature infinite range Sherrington-Kirkpatrick (SK) model when $q(0)=(1 / \sqrt{2})\left(h / T_{\mathrm{G}}^{0}\right)^{2 / 3}$ equals $q(1)=1-(T / J)$, where $h$ is the field, $T_{\mathrm{G}}^{0}$ the freezing temperature, and $J^{2} / N$ is the variance of the strength of interaction between each pair of spins (for appropriate normalization $T_{\mathrm{G}}^{0}=J$ ). The Parisi analysis has been extended to an $m$ 
vector spin-glass in a field recently by Elderfield and Sherrington [11]. They find the longitudinal order parameter in the region $1-\left(T / T_{\mathrm{G}}^{0}\right) \gtrsim\left(h / T_{\mathrm{G}}^{0}\right)^{2 / 3}$ to be effectively pinned at $q(0)=[(m+2) / 2 \sqrt{3}]^{2 / 3}\left[h / T_{\mathrm{G}}^{0}\right]^{2 / 3}$. Noting that $q(1) \sim 1-\left(T / T_{\mathrm{G}}^{0}\right)$, one sees that a "crossover " condition can occur when the two limiting order parameters are equal. Thus, the De Almeida-Thouless relationship between $H_{\mathrm{c}}$ and $T_{\mathrm{c}}$ for the Ising model may be preserved in the $m$ vector spin-glass with perhaps only a change in prefactor.

It we now make the Sompolinsky interpretation of the Parisi parameter $x$, we are then led to the following rationale for the time dependent prefactor $f(t)$ in equation (1). Sompolinsky suggests that $x=1$ be associated with short times where linear response is obeyed, and $x=0$ with long times appropriate to the thermodynamic limit. The shape of $q(x)$ exhibits " a plateau " at and below $x=1$ (short times), with a decrease to $q(0)$ at $x \rightarrow 0$ (long times). We suggest that at fixed time (given $x$ ) cross-over takes place when $q(0)=q(x)$; that is, when $q(0) \sim\left(h / T_{\mathrm{G}}^{0}\right)^{2 / 3}$ equals $q(x) \propto q(1)$. In other words, we argue that, for $h \rightarrow 0, q(x)$ depends only on $T / T_{\mathrm{G}}^{0}$, and when $h$ increases from zero, the cross-overoccurs when $\left(h / T_{\mathrm{G}}^{0}\right)^{2 / 3}$ becomes equal to $q(x)$ at that value of $t_{\mathrm{m}}$ which specifies $x$ (the Sompolinsky association). This leads directly to a preservation of the $\mathrm{De}$ Almeida-Thouless form for the relation between $H_{\mathrm{c}}$ and $T_{\mathrm{c}}$, provided one takes a time dependent prefactor for $1-\left(T / T_{\mathrm{G}}^{0}\right)$. Said another way, $q(x) \rightarrow q(t)=f(t)\left[1-\left(T / T_{\mathrm{G}}^{0}\right)\right]$, where $f(t)$ is a decreasing function of time. The cross-over condition $q(0) \sim q(t)$ then gives the relationship between $H_{\mathrm{c}}$ and $T_{\mathrm{c}}$ exhibited in equation (1). Figure 3 suggests that $q(x) \propto f(t)$ is essentially constant at the linear response value for time less than $10 \mathrm{~ms}$, and decreases significantly for longer time scales (smaller $x$ ). This is consistent with the shape used for $q(x)$ by Parisi [1], Thouless, De Almeida and Kosterlitz [10] and Elderfield and Sherrington [11].

This interpretation is not consistent with the infinite range SK exchange model. Mackenzie and Young have recently shown [12] that all relaxation times should diverge in the thermodynamic limit along and below the De Almeida-Thouless line. However, $\mathrm{Eu}_{0.4} \mathrm{Sr}_{0,6} \mathrm{~S}$ is a short range exchange system. Our results exhibit a transition line of the same form as the infinite range model, leading one to suggest that the De Almeida-Thouless relation may continue to apply to the short range case, but with a time-dependent scaling coefficient (our $f(t)$ ), and that a critical time scale exists below which this prefactor remains constant.

Acknowledgments. - We wish to acknowledge very helpful correspondence with D. Sherrington and valuable discussions with him, and H. Alloul, H. Bouchiat, J. Ferré, M. Gabay, P. Monod, R. Rammal, J. C. Rivoal, G. Toulouse and A. P. Young. We also wish to acknowledge H. Maletta who kindly provided us with the $\mathrm{Eu}_{0.4} \mathrm{Sr}_{0.6} \mathrm{~S}$ sample and $\mathrm{J}$. $\mathrm{L}$. Tholence who has informed us on similar measurements on $\mathrm{CuMn}$ and $\mathrm{Fe}_{70} \mathrm{Ni}_{10} \mathrm{P}_{20}$.

This research was supported in part by the U.S. National Science Foundation and the Office of Naval Research.

\section{References}

[1] Parisi, G., Phys. Rev. Lett. 23 (1979) 1754 ; and J. Phys. A 13 (1980) L115, L1887.

[2] Sompolinsky, H., Phys. Rev. Lett. 47 (1981) 935.

[3] De Almeida, J. R. L. and Thouless, D. J., J. Phys. A 11 (1978) 983.

[4] Toulouse, G. and Gabay, M., Phys. Rev. Lett. 47 (1981) 201.

[5] Cragg, D. M., Sherrington, D. and Gabay, M., Phys. Rev. Lett. 49 (1982) 158.

[6] Chamberlin, R. V., Hardiman, M., Turkevich, L. A. and Orbach, R., Phys. Rev. B 25 (1982) 6720.

[7] Badoz, J., Billardon, M., Canit, J. C. and Russel, M. F., J. Optics 8 (1977) 373.

[8] Bontemps, N., Rivoal, J. C., Billardon, M., Rajchenbach, J. and Ferré, J., J. Appl. Phys. 52 (3) (1981) 1760 . 
[9] Ferré, J., Rajchenbach, J. and Maletta, H., J. Appl. Phys. 52 (3) (1981) 1697.

RAJCHENBACH, J., Thèse de 3e cycle, Univ. Paris-Sud (1980).

[10] Thouless, D. J., De Almeida, J. R. L. and Kosterlitz, J. M., J. Phys. C 13 (1980) 3271.

[11] Elderfield, D. and SherRINGTON, D., submitted for publication (1982).

[12] Mackenzie, N. D. and Young, A. P., Phys. Rev. Lett. 49 (1982) 301. 